\title{
EVALUATION OF THE RESULTS OF MYCOBACTERIUM TUBERCULOSIS DIRECT TEST (MTD) AND MYCOBACTERIAL CULTURE IN URINE SAMPLES
}

\author{
Asli Gamze Sener*; Nukhet Kurultay; Ilhan Afsar \\ Ataturk Training and Research Hospital, Microbiology and Clinical Microbiology Laboratory Izmir/Turkey
}

Submitted: January 04, 2008; Returned to authors for corrections: April 09, 2008; Approved: November 02, 2008.

\section{SHORT COMMUNICATION}

\begin{abstract}
Tuberculosis remains a public health problem in Turkey. Rapid detection of Mycobacterium tuberculosis plays a key role in control of infection. In this article, the Gen-Probe Amplified Mycobacterium Tuberculosis Direct Test (MTD) was evaluated for detection of M. tuberculosis in urine samples. The performance of the MTD was very good and appropriate for routine laboratory diagnosis.
\end{abstract}

Key words: Urinary tuberculosis, MTD test, culture, AFB smear.

Tuberculosis remains a public health problem in Turkey. Rapid detection of Mycobacterium tuberculosis plays a key role in control of infection. Rapid diagnosis of extrapulmonary tuberculosis has a greater impact on patient management than on limiting spread of the disease. AFB smear results should be available within $24 \mathrm{~h}$, but a positive result is not specific for tuberculosis. Mycobacterial culture and identification results, which provide a specific diagnosis, are not available for 2 to 3 weeks or longer. The Gen-Probe Amplified Mycobacterium Tuberculosis Direct Test (MTD) has been widely used as a rapid test for the identification of Mycobacterium tuberculosis. The present study was performed in order to evaluate the routine use of MTD test in urine samples.

Urine samples were collected from the patients that were suspected from urinary tract tuberculosis. Specimens were initially processed by using the $N$-acetyl-L-cysteine $\mathrm{NaOH}$ procedure for digestion and decontamination (4). Samples were inoculated in Lowenstein-Jensen solid culture medium. Mycobacterial cultures were incubated for 6 weeks. All cultures were identified by biochemical tests such as production of niacin, reduction of nitrate and production of heat labile catalase. In addition acid-fast bacilli (AFB) smear was performed and evaluated.
On the other hand the direct Gen-Probe MTD test was performed by following the manufacturer's procedures explicitly (3). Each MTD test run included positive and negative amplification controls and hybridization controls, and in addition, each patient's urine sample was tested for potential MTD test inhibition by spiking a portion of the sample with the M. tuberculosis positive-control suspension. Interpretation of results was as follows: $<30,000$ relative light units (RLU), negative; $\geq 500,000$ RLU, positive; 30,000 to 499,999 RLU, equivocal. For samples yielding an equivocal result, a second aliquot of a decontaminated or fresh specimen was tested; if the second result was $\geq 30,000 \mathrm{RLU}$, the sample was considered positive, whereas if it was $<30,000 \mathrm{RLU}$, it was negative. MTD results were acceptable when the negative control was $<20,000$ RLU and the positive control was $\geq 500,000$ RLU $(>1,000,000$ after September 1999, at which time the manufacturer's directions changed). Multiple MTD test kits with different lot numbers were used for the direct tests on patients' urine samples.

Totaly 180 urine samples were evaluated. AFB smear, culture and MTD test were positive in 13 (7.2\%) of 180 samples (Table 1 and 2). Two specimens (1.1\%) were AFB smear- negative, MTD-positive, culture-positive. One sample was AFB smear-

*Corresponding Author. Mailing address: Ataturk Training and Research Hospital, Microbiology and Clinical Microbiology Laboratory Izmir/Turkey. GSM +90 532302 4434. E-mail: agsener@gmail.com 
positive and culture-positive, but the MTD test was equivoval. When repetead the MTD test result was positive.

Results were evaluated statistically by chi-square test $(\mathrm{p}<0.05)$. According to statistical evaluation MTD test was suggested in urine samples.

For many years the AFB smear has been the only rapid diagnostic test available. Woods (13) informed that the sensitivity of AFB smears varies from about 25 to $80 \%$. Since the introduction of the MTD test into diagnostic mycobacteriology, many publications have confirmed its high sensitivity and specificity. Compared to culture, the sensitivity of the MTD test ranged from 65 to $97 \%$ in different studies, whereas its specificity was always high $(2,5,8)$.

Coll et al. (1) reported that, the overall sensitivities, specificities, and positive and negative predictive values for extra-pulmonary specimens $(\mathrm{n}=1350)$ were $67.4,99.9,98.2$, and $97.9 \%$, respectively. The lower sensitivity of the test in nonrespiratory samples was mainly due to the performance in smear-negative specimens. In that study the sensitivity of the test in nonpulmonary AFB smear-positive samples was 93.5\%, similar to the $99.4 \%$ obtained in AFB smear-positive respiratory samples. Nucleic acid amplification techniques have excellent specificity but only moderate sensitivity in AFB smear-negative samples (12). In these specimens, particularly nonpulmonary, the sensitivity of the test is limited but the benefits of a positive

Table 1. Gen-Probe MTD, smear, and culture results for urýne specimens.

\begin{tabular}{cccc}
\hline number & AFB smear & Culture & MTD \\
\hline 13 & positive & positive & positive \\
2 & negative & positive & positive \\
1 & positive & positive & equivocal \\
16 & & & \\
\hline
\end{tabular}

Table 2. Results of statistical analysis.

\begin{tabular}{lccccccccc}
\hline & \multicolumn{8}{c}{ MTD } \\
\hline & \multirow{4}{*}{ Result } & \multicolumn{7}{c}{-} & \multicolumn{4}{c}{ Total } & \multirow{2}{*}{ p } \\
\cline { 3 - 8 } & & $\mathrm{n}$ & $\%$ & $\mathrm{n}$ & $\%$ & $\mathrm{n}$ & $\%$ & \\
\hline \multirow{4}{*}{ AFB } & - & 164 & 91,11 & 2 & 1,11 & 166 & 92,22 & 0,000 \\
& + & 0 & 0,00 & 14 & 7,78 & 14 & 7,78 & \\
& Total & 164 & 91,11 & 16 & 8,89 & 180 & 100,00 & \\
\multirow{4}{*}{ CULTURE } & - & 164 & 91,11 & 0 & 0,00 & 164 & 91,11 & 0,000 \\
& + & 0 & 0,00 & 16 & 8,89 & 16 & 8,89 & \\
& Total & 164 & 91,11 & 16 & 8,89 & 180 & 100,00 & \\
\hline
\end{tabular}

result probably make the test cost effective (1). Pfyffer et al. (7) tested 53 urine specimens and observed that, eight were MTD positive and culture positive. Of these eight specimens, five were smear positive and three were smear negative. There were three false positive results. One of them was negative upon retesting; the other two could, however, be considered true positives, since one patient (HIV infected) had been diagnosed with disseminated tuberculosis 13 months earlier. In the other true positive case, the patient's chest $\mathrm{X}$ ray showed extensive pulmonary cavities. Pounder et al. (9) tested 172 specimens and reported that the evaluated sensitivity, specificity, and positive and negative predictive values of MTD were $98.0 \%$, $99.2 \%, 98.0 \%$, and $99.2 \%$, respectively in another study (6), sensitivity of the MTD method was found to be $83.33 \%$ in respiratory samples and $54.54 \%$ in nonrespiratory samples. Sensitivity and specificity values detected in the nonrespiratory samples in same study were $54.54 \%$ and $88.23 \%$, respectively. Surucuoglu et al. (11) informed that, for 97 extrapulmonary specimens, sensitivity and specificity of amplified MTD test were $60 \%$ and $100 \%$, respectively. The authors emphasized that culture positive extrapulmonary specimens were sparse in their study.

The results of this study and additional similar studies that include more specimens of urine samples, indicate that MTDtest can provide correct results. However, for optimum results, a close cooperation between the clinician and the laboratory is needed to define the specimens that need urgent screening by MTD (7). Despite the fact that the nucleic acid amplification tests are approved only for respiratory specimens, many investigators have used them to test specimens from other sites $(2,10)$.

In conclusion, despite the use of conventional diagnostic techniques in routine tuberculosis laboratory, MTD is a reliable method for rapid detection of $M$. tuberculosis in urine specimens when clinical data are incorporated.

\section{RESUMO}

\section{Avaliação de resultados do Teste Direto para Mycobacterium tuberculosis (MTD) e da cultura para micobacterias em amostras de urina}

A tuberculose continua sendo um problema de saúde pública na Turquia. A detecção rápida de Mycobacterium tuberculosis tem um papel importante no controle da infecção. Nesse artigo, avaliou-se o Gen-Probe Amplified Mycobacterium Tuberculosis Test (MTD) para deteç̧ão de M. tuberculosis em amostras de urina. O desempenho do MTD foi muito bom e adequado para diagnóstico laboratorial de rotina.

Palavras-chave: tuberculose urinária, Teste MTD, cultura, esfregaço AFB 


\section{REFERENCES}

1. Coll, P.; Garrigo, M.; Moreno, C.; Marti, N. (2003). Routine use of Gen-Probe Amplified Mycobacterium Tuberculosis Direct (MTD) test for detection of Mycobacterium tuberculosis with smear-positive and smear-negative specimens. Int. J. Tuberc. Lung. Dis., 7(9): 886-891.

2. Gamboa, F.; Fernandez, G.; Padilla, E.; Manterola, J.M.; Lonca, J.; Cardona, P.J.; Matas, L.; Ausina, V. (1998). Comparative evaluation of initial and new versions of the Gen-Probe Amplified Mycobacterium Tuberculosis Direct Test for direct detection of Mycobacterium tuberculosis in respiratory and nonrespiratory specimens. J. Clin. Microbiol., 36(3): 684-689.

3. Gen-Probe. (1998). Amplified Mycobacterium Tuberculosis Direct Test for in vitro diagnostic use: 50-test kit (revised package insert). Gen-Probe, San Diego, Calif.

4. Nolte, F.S.B.; Metchock, B. (1995). Mycobacterium, In Murray, P.R.; Baron, E.J.; Pfaller, M.A.; Tenover, F.C.; Yolken, R.H. (eds) Manual of clinical microbiology, 6th ed. Am. Soc. Microbiol., Washington, D.C. p. 400-437.

5. O'Sullivan, C.E.; Miller, D.R.P.S.; Schneider, P.S.; Roberts, G.D. (2002). Evaluation of Gen-Probe Amplified Mycobacterium Tuberculosis Direct Test by using respiratory and nonrespiratory specimens in a tertiary care center laboratory. J. Clin. Microbiol., 40(5): 1723-1727.

6. Ozekinci, T.; Mese, S.; Atmaca, S.; Akpolat, N.; Gul, K. (2007). Evaluation of the Ehrlich-Ziehl-Neelsen (EZN) and Amplified Mycobacterium tuberculosis Direct Test According to the BACTEC Method in Respiratory and Nonrespiratory Samples. Turk. J. Med. Sci., 37(3): 145-149

7. Pfyffer, G.E.; Kissling, P.; Jahn, E.M.; Welscher, H.M.; Salfinger, M.; Weber, R. (1996). Diagnostic performance of amplified
Mycobacterium tuberculosis direct test with cerebrospinal fluid, other nonrespiratory and respiratory specimens. J. Clin. Microbiol., 34: 834-841.

8. Piersimoni, C.; Callegaro, A.; Scarparo, C.; Penati, V.; Nista, D.; Bornigia, S.; Lacchini, C.; Scagnelli, M.; Santini, G.; De Sio, G. (1998). Comparative evaluation of the new Gen-Probe Mycobacterium Tuberculosis Amplified Direct Test and the semiautomated Abbott LCx Mycobacterium tuberculosis assay for direct detection of Mycobacterium tuberculosis complex in respiratory and extrapulmonary specimens. J. Clin. Microbiol., 36(12): 3601-3604.

9. Pounder, J.I.; Aldous, W.K.; Woods, G.L. (2006). Comparison of real-time polymerase chain reaction using the Smart Cycler and the Gen-Probe amplified Mycobacterium tuberculosis direct test for detection of $M$. tuberculosis complex in clinical specimens. Diagn. Microbiol. Infect. Dis., 54: 217-222.

10. Scarparo, C.; Piccoli, P.; Rigon, A.; Ruggiero, G.; Scagnelli, M.; Piersimoni, C. (2000). Comparison of enhanced Mycobacterium tuberculosis Amplified Direct Test with COBAS AMPLICOR Mycobacterium tuberculosis assay for direct detection of Mycobacterium tuberculosis complex in respiratory and extrapulmonary specimens. J. Clin. Microbiol., 38(4): 1559-1562.

11. Sürücüoglu, S.; Ozkütok, N.; Gazi, H.; Celik, P. (2007). Assessment of performance of "amplified Mycobacterium tuberculosis direct test" in pulmonary and extrapulmonary specimens. Mikrobiyol Bul., 41(3): 377-84

12. Woods, G.L. (2001). Molecular techniques in mycobacterial detection. Arch. Pathol. Lab. Med., 125: 122-126.

13. Woods, G.L.; Pentony, E.; Boxley, M.J.; Gatson A.M. (1995) Concentration of sputum by cytocentrifugation for preparation of smears for detection of acid-fast bacilli does not increase sensitivity of the fluorochrome stain. J. Clin. Microbiol., 33(7): 1915-1916. 